\title{
Temperature-Induced Structural Transitions in the Gallium-Based MIL-53 Metal-Organic Framework
}

\author{
Anne Boutin* and David Bousquet \\ Ecole Normale Supérieure, Département de Chimie, UMR 8640, CNRS-ENS-UPMC, 24, rue Lhomond, 75005 Paris, France
}

Aurélie U. Ortiz, François-Xavier Coudert, and Alain H. Fuchs

CNRS and Chimie ParisTech, 11 rue Pierre et Marie Curie, 75005 Paris, France

Anthony Ballandras, Guy Weber, Igor Bezverkhyy, and Jean-Pierre Bellat

Laboratoire Interdisciplinaire Carnot de Bourgogne (ICB), UMR 6303 CNRS Université de Bourgogne, 9 av. Alain Savary, BP 47870, 21078 Dijon Cedex, France

Guillaume Ortiz, Gérald Chaplais, Jean-Louis Paillaud, Claire Marichal, Habiba Nouali, and Joël Patarin

Univ de Haute Alsace (UHA), CNRS, Equipe Matériaux à Porosité Contrôlée (MPC), Institut de Science des Matériaux de Mulhouse (IS2M), UMR 7361, 3 rue Alfred Werner, 68093 Mulhouse Cedex, France

\section{Supporting Information}

\begin{abstract}
We report a structural and thermodynamic investigation of the phase behavior of $\mathrm{Ga}(\mathrm{OH}, \mathrm{F})-\mathrm{MIL}-53$, a gallium-based metal-organic framework (MOF) having the MIL-53 topology containing 0.7 wt \% fluorine bonded to the metal. Despite some small structural differences, especially for the hydrated form, the overall physical chemistry behavior of $\mathrm{Ga}(\mathrm{OH}, \mathrm{F})-\mathrm{MIL}-53$ is very similar to standard fluorine free Ga-MIL-53 material. A combination of in situ X-ray diffraction, in situ Fourier transform infrared spectroscopy, differential scanning calorimetry, and heat capacity measurements allowed us to establish that $\mathrm{Ga}(\mathrm{OH}, \mathrm{F})-\mathrm{MIL}-53$ under vacuum

(i.e., the empty material) exhibits two stable phases: a nonporous narrow-pore (np) phase favored at low temperature and a large-pore (lp) phase favored at high temperature, accompanied by a huge hysteresis effect. Structure determination of the hydrated material $\mathrm{Ga}(\mathrm{OH}, \mathrm{F})-\mathrm{MIL}-53$ np__ $\mathrm{H}_{2} \mathrm{O}$ obtained after synthesis, activation, and rehydration was also performed. Density functional theory calculations show that it is not a stable structure of $\mathrm{Ga}(\mathrm{OH}, \mathrm{F})-\mathrm{MIL}-53$ in the absence of adsorbed water molecules. Instead, this hydrated structure is a swollen variant of the np phase, where the flexible framework has expanded to accommodate water molecules.
\end{abstract}

\section{INTRODUCTION}

Within the last 15 years, the development of a new class of organic-inorganic hybrid compounds called metal-organic frameworks (MOFs) has experienced a large acceleration. ${ }^{1-4}$ Such solids are synthesized from metal and organic sources and give rise to one-dimensional, two-dimensional, or threedimensional porous structures where the inorganic subnetwork is made up of clusters, chains, layers, or even three-dimensional networks. The tremendous interest in this family of solids can be related to their extremely large range of crystal structures and host-guest properties, giving them a major potential impact in adsorption/separation technologies for strategic gases (e.g., $\mathrm{H}_{2}, \mathrm{CO}_{2}$, and $\mathrm{CH}_{4}$ ) linked with energy supply and environmental problems. ${ }^{5,6}$ The combination of tunable porosity, functionalization of the internal surface, together with structural flexibility of the host framework opens the way to an extremely rich host-guest chemistry, putting this class of materials in a unique position. Depending on their characteristics (porosity, structure, nature of the organic linker), many subtypes of MOFs have been defined in the literature as PCPs (porous coordination polymers), MMOFs (microporous MOFs), ZMOFs (zeolite-like MOFs), ZIFs (zeolitic imidazolate frameworks), or SPCs (soft porous crystals).

Received: December 11, 2012

Revised: March 26, 2013

Published: March 28, 2013 
This last-mentioned family consists of materials behaving in a remarkable guest-responsive fashion. Soft porous crystals ${ }^{1}$ exhibit a variety of large amplitude dynamic behaviors of their frameworks in response to external stimuli of weak intensity (light, electric field, gas exposure, ...). The change in the framework of SPCs in response to the external constraint is reversible and maintains the crystalline character of the solid. As an example, one may cite the MIL-53 type frameworks ${ }^{2,7-11}$ which exhibit guest-induced structural phase transitions upon guest adsorption and desorption, called "breathing" transitions. The bistable behavior of this system is controlled by the gas pressure that acts as the external stimulus, but temperature, mechanical stress, and liquid-phase adsorption can also induce structural transitions. ${ }^{12-14}$

The solids of the MIL-53 type family are obtained from terephthalic acid $\left(\mathrm{H}_{2} \mathrm{BDC}\right)$ and a variety of metals such as $\mathrm{Al}$, $\mathrm{Cr}, \mathrm{Fe}, \mathrm{Ga}, \mathrm{V}, \mathrm{In}, \mathrm{Sc}, \mathrm{Mn}$, ... It has been shown that the nature of the metal strongly affects the behavior of the solid ${ }^{15-17}$ as well as functionality of the linker molecules. ${ }^{18-21}$

In 2008, Vougo-Zanda et al. ${ }^{22}$ published the syntheses and the structures determined by single-crystal X-ray diffraction of two gallium-based MOFs having the MIL-53 topology, that is, $\mathrm{Ga}(\mathrm{OH})(\mathrm{BDC}) \cdot 0.74 \mathrm{H}_{2} \mathrm{BDC}$ and $\mathrm{Ga}(\mathrm{OH}, \mathrm{F})(\mathrm{BDC}) \cdot 0.74$ $\mathrm{H}_{2} \mathrm{BDC}$. Since then, several teams published gallium-containing MIL-53 type materials, in particular, Férey's group, the pioneer team of the MIL-53 family, ${ }^{23}$ and our group with the synthesis of gallium-containing MIL-53, named IM-19. ${ }^{9,24,25}$ In the present paper we report a study of the latter material named hereafter $\mathrm{Ga}(\mathrm{OH}, \mathrm{F})-\mathrm{MIL}-53$, which partially contains fluorine in the framework in contrast to the conventional Ga-MIL-53 ${ }^{23}$ that is fluorine free and the $\mathrm{Al}(\mathrm{F})-\mathrm{MIL}-53$ in which all the $\mathrm{OH}$ groups are replaced by fluorine atoms. ${ }^{26}$

One of the specificities of the gallium-based MIL-53 is that upon dehydration a narrow pore (np) structure is observed at room temperature, in contrast to well-studied aluminum- or chromium-based MIL-53 for which the stable phase of the bare material at room temperature is an open form (large pore, lp). Structure characterization of gallium-based MIL-53 has been performed in the presence of $\mathrm{H}_{2} \mathrm{BDC}$ (benzenedicarboxylic acid), DMF (dimethylformamide), or water and without guest molecules. ${ }^{9,23}$ Depending on the presence or not of guest molecules, their nature, and temperature, an expansion/ shrinkage phenomenon is observed. However, some questions still subsist about the thermodynamics of the solid-solid phase transition in the empty material (i.e., under vacuum): its reversibility and its energetics.

In the present paper, we have used a combination of experimental and theoretical tools to shed light onto these issues. We performed a complete study of the solid-solid phase transition in $\mathrm{Ga}(\mathrm{OH}, \mathrm{F})-\mathrm{MIL}-53$ under secondary vacuum in a large temperature range, by using in situ X-ray diffraction (XRD), in situ Fourier transform infrared spectroscopy (FTIR), differential scanning calorimetry (DSC), as well as density functional theory (DFT) calculations.

\section{EXPERIMENTAL AND THEORETICAL DETAILS}

Synthesis. All reagents and chemicals were used without any further purification. The metal source, gallium nitrate hydrate $\mathrm{Ga}\left(\mathrm{NO}_{3}\right)_{3} \cdot x \mathrm{H}_{2} \mathrm{O}(99.99 \%)$, was purchased from Strem Chemicals. The organic linker, $\mathrm{H}_{2} \mathrm{BDC}$ (99\%), was supplied by Fluka. The solvents, DMF $(\geq 99 \%)$ and ethanol (EtOH, $\geq 99.8 \%$ ), were provided by Sigma-Aldrich and VWR, respectively. Hydrofluoric acid (HF, 40\%) was purchased from Prolabo.

$\mathrm{Ga}(\mathrm{OH}, \mathrm{F})-\mathrm{MIL}-53 \_n p_{-} \mathrm{H}_{2} \mathrm{O}$. The crude form of $\mathrm{Ga}(\mathrm{OH}, \mathrm{F})-$ MIL-53 (i.e., $\mathrm{Ga}(\overline{\mathrm{OH}}, \overline{\mathrm{F}})-\mathrm{MIL}-53$ lp_ $\mathrm{H}_{2} \mathrm{BDC}$ ) was hydrothermally prepared from a mixture of $\mathrm{Ga}\left(\mathrm{NO}_{3}\right)_{3} \cdot x \mathrm{H}_{2} \mathrm{O}(8.19$ g; $32.02 \mathrm{mmol}$ by assuming $x=0), \mathrm{H}_{2} \mathrm{BDC}(10.64 \mathrm{~g}$; 64.04 $\mathrm{mmol})$, and HF ( $1.60 \mathrm{~g} ; 32.02 \mathrm{mmol})$ in deionized water in a $1 / 2 / 1 / 100$ molar ratio. The mixture was heated at $493 \mathrm{~K}$ for 3 days in a Teflon-lined stainless steel autoclave. The solid was filtered, washed with hot DMF (for removing the unreacted molecules of $\mathrm{H}_{2} \mathrm{BDC}$ ) and ethanol, and dried at room temperature. White crystals were obtained with a yield of $45 \%$ based on $\mathrm{Ga}(5.35 \mathrm{~g} ; 14.25 \mathrm{mmol})$. Then, the as-made material was treated with DMF in a Teflon-lined stainless steel autoclave at $433 \mathrm{~K}$ for 6 days. The solid (i.e., Ga(OH,F)-MIL53 lp_DMF) was recovered by filtration, washed with DMF, and dried at room temperature. Finally, $\mathrm{Ga}(\mathrm{OH}, \mathrm{F})-\mathrm{MIL}$ 53_np_ $\mathrm{H}_{2} \mathrm{O}$ was obtained from $\mathrm{Ga}(\mathrm{OH}, \mathrm{F})-\mathrm{MIL}-53$ _lp_DMF after removal of DMF by immersion in $\mathrm{EtOH}$ at room temperature during $24 \mathrm{~h}$. After filtration, the white crystals were heated in air at $548 \mathrm{~K}$ for 1 day. After cooling, a white crystalline powder was recovered. The presence of the fluoride anion was evidenced by ${ }^{19} \mathrm{~F}$ NMR spectroscopic analyses in both liquid (after dissolution of the solid) and solid phases, the former characterization technique having enabled in addition the quantification of fluorine in the hydrated solid (Figures S1 and S2, Supporting Information). These results combined with the one of thermogravimetric analysis (not shown) converge on the following formula, $\mathrm{Ga}\left(\mathrm{OH}_{0.9} \mathrm{~F}_{0.1}\right)(\mathrm{BDC}) \cdot 0.9 \mathrm{H}_{2} \mathrm{O}$, for $\mathrm{Ga}$ $(\mathrm{OH}, \mathrm{F})-\mathrm{MIL}-53$ np_ $\mathrm{H}_{2} \mathrm{O}$. It is worth noting that elemental analysis performed in the work of ref 9 did not allow evidencing the traces of fluorine that ${ }^{19} \mathrm{~F}$ NMR clearly shows here.

Powder XRD and Rietveld Refinement. High-resolution powder XRD pattern of $\mathrm{Ga}(\mathrm{OH}, \mathrm{F})-\mathrm{MIL}-53$ np_ $\mathrm{H}_{2} \mathrm{O}$ was first recorded by collecting the data on a STOE STADI-P diffractometer equipped with a curved monochromator $\mathrm{Ge}(111)$ and a linear position-sensitive detector, in the 8$90^{\circ}(2 \theta)$ range (step size: $0.01^{\circ}$, time acquisition/step: $150 \mathrm{~s}$ ) and in the Debye-Scherrer scan mode by using $\mathrm{Cu} \mathrm{K} \alpha_{1}$ radiation $(\lambda=0.15406 \mathrm{~nm})$. The Rietveld refinement was performed with the GSAS package. ${ }^{27}$ More details on data collection are given in the Supporting Information. The final Rietveld refinement gave excellent reliability factors; the final Rietveld plot is displayed in Figure S3, and crystal as well as Rietveld refinement parameters are listed in Table S1 (Supporting Information). Atomic parameters are listed in Table S2, and selected bond distances and angles are given in Table S3 (Supporting Information). Figure S4 (Supporting Information) displays the asymmetric unit of $\mathrm{Ga}(\mathrm{OH}, \mathrm{F})-\mathrm{MIL}$ 53 np_ $\mathrm{H}_{2} \mathrm{O}$. A crystallographic information file (CIF file) of $\mathrm{Ga}(\mathrm{O} \overline{\mathrm{H}}, \mathrm{F})-\mathrm{MIL}-53$ np_ $\mathrm{H}_{2} \mathrm{O}$ can be obtained from the Cambridge Crystallographic Data Centre, quoting deposition numbers CCDC 912634.

Besides, in situ XRD patterns were recorded using $\mathrm{Cu} \mathrm{K} \alpha$ radiation on a D8 Advance Bruker apparatus equipped with a Vantec linear detector. Measurements were performed under vacuum $\left(<10^{-3} \mathrm{hPa}\right)$ at increasing then decreasing temperatures within the thermal stability temperature range $298-573$ $\mathrm{K}$, by using a MRI TC-Radiation chamber.

FTIR. In situ FTIR absorption measurements were performed in an optical cell specially built to study the interaction of a gas on a nanoporous material. This cell is a stainless steel six-way cube equipped with two $\mathrm{KBr}$ windows 
a)

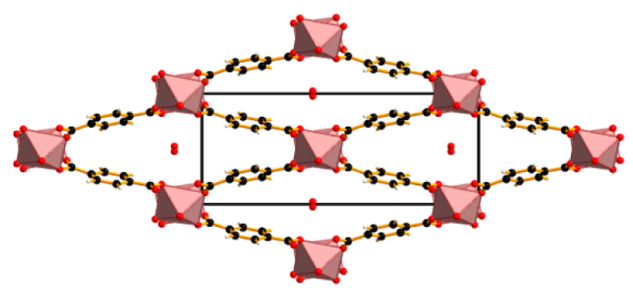

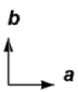

b)

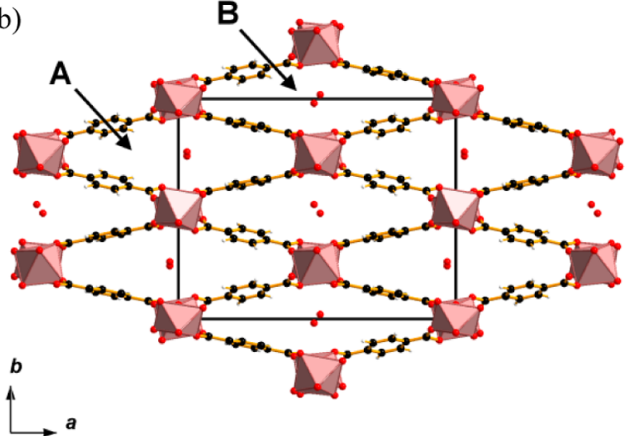

Figure 1. Structural representations of (a) $\mathrm{Ga}(\mathrm{OH}, \mathrm{F})-\mathrm{MIL}-53 \_n p \_\mathrm{H}_{2} \mathrm{O}$ and (b) Ga-MIL-53_np_ $\mathrm{H}_{2} \mathrm{O}$.

Table 1. Unit Cell Parameters of Ga(OH,F)-MIL-53_np_H $\mathrm{H}_{2} \mathrm{O}$, Ga-MIL-53_np_ $\mathrm{H}_{2} \mathrm{O}$, and Al-MIL-53_np_ $\mathrm{H}_{2} \mathrm{O}^{a}$

\begin{tabular}{|c|c|c|c|}
\hline material & \multirow[b]{2}{*}{ unit cell volume $\left(\AA^{3}\right)$} & \multirow[b]{2}{*}{ space group } & \multirow[b]{2}{*}{ unit cell parameters $\left(\AA\right.$ and $\left.^{\circ}\right)$} \\
\hline original name in italic & & & \\
\hline $\begin{array}{l}\text { Ga-MIL-53(Ga)_lp_pyr containing pyridine } \\
\text { Ga-MIL-53_lp MIL-53(Ga)_ht } t^{23} \text { high temperature }\end{array}$ & $\begin{array}{l}1449.2 \\
1479.7\end{array}$ & Imma & $\begin{array}{l}a=17.29, b=6.73, c=12.46^{22} \\
a=6.72, b=16.68, c=13.21^{23}\end{array}$ \\
\hline $\begin{array}{l}\mathrm{Ga}(\mathrm{OH}, \mathrm{F})-\mathrm{MIL}-53 \text { lp } \\
\text { phase } \mathrm{p}^{9} \text { (high-temperature activation; room-temperature } \\
\text { measurement) }\end{array}$ & 1502.7 & Imma & $a=6.75, b=16.68, c=13.35$ \\
\hline $\begin{array}{l}\text { Ga-MIL-53_np_empty } \\
M I L-53(G a) \_l t^{23}\end{array}$ & 886.3 & $\mathrm{C} 2 / \mathrm{c}$ & $a=19.83, b=6.86, c=6.71, \beta=103.88^{23}$ \\
\hline $\begin{array}{l}\text { Ga-MIL-53_np_H } \mathrm{H}_{2} \mathrm{O} \\
M I L-53(\mathrm{G} a)\left\{\mathrm{H}_{2} \mathrm{O}\right\}^{23}\end{array}$ & $1938.8(=2 \times 969.4)$ & $P 2_{1} / c$ & $a=19.71, b=15.16, c=6.68 \beta=103.79^{23}$ \\
\hline $\begin{array}{l}\mathrm{Ga}(\mathrm{OH}, \mathrm{F}) \text {-MIL-53_np_empty } \\
\text { phase } 1^{9}\end{array}$ & 895.9 & $C c$ & $a=19.77, b=6.97, c=6.70, \beta=103.95^{b}$ \\
\hline $\begin{array}{l}\mathrm{Ga}(\mathrm{OH}, \mathrm{F})-\mathrm{MIL}-53 \_n \mathrm{np}_{-} \mathrm{H}_{2} \mathrm{O} \\
\text { phase } h^{9}\end{array}$ & 973.4 & $C c$ & $a=19.66, b=7.64, c=6.67, \beta=103.88$ \\
\hline Al-MIL-53_np_ $\mathrm{H}_{2} \mathrm{O}$ & 946.7 & $C_{c}$ & $a=19.51, b=7.61, c=6.58, \beta=104.24^{36}$ \\
\hline
\end{tabular}

MIL-53(Al) $-1 t^{36}$

${ }^{a}$ Double cell. ${ }^{b}$ Unit cell parameters refined with the Le Bail method (GSAS, ${ }^{27} a=19.77488(22) \AA, b=6.96751(8) \AA, c=6.70007(8) \AA, \beta=$ $103.9429(12)^{\circ}, V=895.947(19) \AA^{3}$, Rwp $\left.=0.0591, \mathrm{Rp}=0.0392, \chi^{2}=4.254\right)$. See Figure S5 (Supporting Information) for final refinement plot.

and two view ports for high vacuum, each of them being placed on opposite sides of the cube. The lower part of the cube is closed by means of a fixed solid flange, and the upper part is connected to a heat chamber and to both a vacuum line and a gas inlet. The windows are located at a short distance from each other of about $10 \mathrm{~mm}$ to optimize the signal-to-noise ratio and to allow the exploration of a wide domain of pore filling of the adsorbent. The sample is dispersed between two $\mathrm{KBr}$ discs and placed in the sample holder, which can be moved up and down from the heat chamber to the optical cell, by using a magnetic sample transporter. After a thermal treatment under vacuum up to $573 \mathrm{~K}$ the sample holder is moved to the optical cell where the spectra are recorded at room temperature over a wide range of controlled pressure from $10^{-4}$ to $10^{3} \mathrm{hPa}$. The FTIR spectrometer was a Bruker Equinox 55 instrument equipped with a globar source, a DTGS detector, and a $\mathrm{KBr}$ beamsplitter. All spectra were recorded at a resolution of $2 \mathrm{~cm}^{-1}$ by summing 40 scans in transmission mode. Each spectrum was referenced to a background spectrum recorded in the same conditions without sample.

DSC. Calorimetric measurements were carried out by means of a C80 Setaram Tian-Calvet differential calorimeter. The sample mass was around $300 \mathrm{mg}$. The heat capacity was measured by increasing the sample temperature step by step from 298 to $553 \mathrm{~K}$. The temperature increment was $10 \mathrm{~K}$, and the heating rate was $0.5 \mathrm{~K} \mathrm{~min}^{-1}$. The change of enthalpy at the phase transition was measured under vacuum by heating the sample from 298 to $553 \mathrm{~K}$ with a heating rate of $0.1 \mathrm{~K} \mathrm{~min}^{-1}$. In all measurements the sample was kept under a dynamic vacuum of $10^{-5} \mathrm{hPa}$. In both cases, blank experiments without sample were performed under the same conditions to take into account the thermal deviation of the calorimetric apparatus.

First-Principles Calculations. Experimental crystallographic structures of the $\mathrm{Ga}(\mathrm{OH}, \mathrm{F})-\mathrm{MIL}-53$ and Ga-MIL-53 materials were fully relaxed by optimizing both atomic positions and unit cell parameters. We performed first-principles calculations in the density functional theory approach with periodic unit cell, full use of the crystals' symmetry elements, and localized basis sets as implemented in the CRYSTAL09 code. $^{28}$ We used the B3LYP hybrid exchange-correlation functional ${ }^{29,30}$ with empirical correction for the dispersive interactions following the scheme of Grimme. ${ }^{31}$ All electron basis sets were used for all atoms involved: 6-311G(d,p) for $\mathrm{H}$, $\mathrm{C}$ and $\mathrm{O},{ }^{32} 8-511 \mathrm{G}^{*}$ for $\mathrm{Al}^{33}$ and $86-4111 \mathrm{~d} 41 \mathrm{G}$ for $\mathrm{Ga}^{34}$

\section{RESULTS AND DISCUSSION}

1. Structure Determinations: Crystallography and First-Principles Calculations. The structure of $\mathrm{Ga}(\mathrm{OH}, \mathrm{F})$ MIL-53 np $\mathrm{H}_{2} \mathrm{O}$ is compared with the one of Ga-MIL53 np $\overline{\mathrm{H}}_{2} \mathrm{O}$, both at room temperature, in Figure 1. Like all the MOFs displaying the MIL-53 topology, it is built from 1D chains of $\mathrm{MO}_{6}(\mathrm{M}=\mathrm{Ga}$ here $)$ octahedra sharing $\mathrm{OH}$ vertices (running along the $c$ axis) which are linked by terephthalate ligands to generate a 3D framework with rhombus-shaped 
Table 2. Unit Cell Volumes, Space Groups, and Parameters for Crystalline Structures Calculated by Quantum Chemistry

\begin{tabular}{|c|c|c|c|c|}
\hline & material & unit cell volume $\left(\AA^{3}\right)$ & $\begin{array}{l}\text { space } \\
\text { group }\end{array}$ & unit cell parameters $\left(\AA\right.$ and $\left.^{\circ}\right)$ \\
\hline Ga-MIL-53_lp & $\begin{array}{l}\text { starting from Ga-MIL-53_lp containing } \\
\text { pyridine }\end{array}$ & 1452.7 & Imma & $a=17.65, b=6.84, c=12.03$ \\
\hline \multirow[t]{2}{*}{ Ga-MIL-53_np_empty } & starting from Ga-MIL-53_np_empty & 899.0 & $\mathrm{C} 2 / \mathrm{c}$ & $a=21.61, b=7.03, c=6.68, \beta=117.57$ \\
\hline & dehydrated from Ga-MIL-53_np_ $\mathrm{H}_{2} \mathrm{O}$ & $1681.4(=2 \times 840.7)$ & $P 2_{1} / c$ & $a=19.40, b=13.27, c=6.66, \beta=101.09$ \\
\hline $\mathrm{Ga}(\mathrm{OH}, \mathrm{F})-\mathrm{MIL}-53$ np_empty & $\begin{array}{l}\text { dehydrated from } \\
\text { Ga(OH,F)-MIL-53_np__ } \mathrm{H}_{2} \mathrm{O}\end{array}$ & 897.9 & $C c$ & $a=21.62, b=7.02, c=6.67, \beta=117.38$ \\
\hline $\mathrm{Ga}(\mathrm{OH}, \mathrm{F})-\mathrm{MIL}-53 \_n p \_\mathrm{H}_{2} \mathrm{O}$ & starting from $\mathrm{Ga}(\mathrm{OH}, \mathrm{F})-\mathrm{MIL}-53 \mathrm{np}_{-} \mathrm{H}_{2} \mathrm{O}$ & 948.6 & $C c$ & $a=20.55, b=7.23, c=6.65, \beta=106.04$ \\
\hline
\end{tabular}

channels. Moreover, liquid and solid state ${ }^{19} \mathrm{~F}$ NMR analyses evidence the presence of fluorine in the framework. The amount of fluorine determined by liquid state ${ }^{19} \mathrm{~F}$ NMR analysis is $0.7 \mathrm{wt} \%$ (Figure S1, Supporting Information) which corresponds to a $\mathrm{F} / \mathrm{OH}$ ratio around $1 / 9$; i.e., one among ten bridged positions is occupied by one fluorine atom (nine others by $\mathrm{OH}$ groups). Besides, it is worth noting that because of, first, the small amount of fluorine in the framework and, second, the similarity of $\mathrm{F}$ and $\mathrm{OH}$ scattering factors the Rietveld refinement of $\mathrm{Ga}(\mathrm{OH}, \mathrm{F})-\mathrm{MIL}-53$ np_ $\mathrm{H}_{2} \mathrm{O}$ based on powder XRD pattern has been carried out without explicitly considering the presence of fluorine. The refined unit cell chemical composition taking into account the fluorine amount obtained from chemical analysis of $\mathrm{Ga}(\mathrm{OH}, \mathrm{F})-\mathrm{MIL}-53 \_\mathrm{np} \mathrm{H}_{2} \mathrm{O}$ is $\mathrm{Ga}\left(\mathrm{OH}_{0.9} \mathrm{~F}_{0.1}\right)(\mathrm{BDC}) \cdot 0.83 \quad \mathrm{H}_{2} \mathrm{O}$ (see Table S1, Supporting Information). The refined number of water molecules is in good agreement with the one obtained by TG analysis.

Both Ga(OH,F)-MIL-53_np_ $\mathrm{H}_{2} \mathrm{O}$ and Ga-MIL$53 \_n p \_\mathrm{H}_{2} \mathrm{O}$ crystallize in the monoclinic system (Table 1). Nevertheless, the main difference resides on different space groups, i.e., the noncentrosymmetric $C c$ group for $\mathrm{Ga}(\mathrm{OH}, \mathrm{F})$ MIL-53_np_ $\mathrm{H}_{2} \mathrm{O}$ and the centrosymmetric $P 2_{1} / c$ group for Ga-MIL-53 np $\mathrm{H}_{2} \mathrm{O}$ with a double unit cell volume. As a result of the lowering of the symmetry, in Ga-MIL53 np_ $\mathrm{H}_{2} \mathrm{O}$, we observe a tripling of the gallium and a doubling of the water crystallographic sites compared with $\mathrm{Ga}(\mathrm{OH}, \mathrm{F})-\mathrm{MIL}-53$ np_ $\mathrm{H}_{2} \mathrm{O}$ for which a unique crystallographic site is observed for gallium and water, respectively. Accordingly, two types of rhombus-shaped channels exist for Ga-MIL-53_np_ $\mathrm{H}_{2} \mathrm{O}$ as depicted in Figure $1 \mathrm{~b}$, whereas only one type of channel appears for $\mathrm{Ga}(\mathrm{OH}, \mathrm{F})-\mathrm{MIL}-53$ np_ $\mathrm{H}_{2} \mathrm{O}$. This could be expressed by the twist angles between the terephthalate linker's planes. Indeed, for $\mathrm{Ga}(\mathrm{OH}, \mathrm{F})-\mathrm{MIL}$ $53 \_n p \_\mathrm{H}_{2} \mathrm{O}$ the angle formed by the neighboring aromatic moieties, i.e., the ligands involved in the sharpest angle of the lozenge, is unique and around $35.3^{\circ}$. For Ga-MIL-53_np_ $\mathrm{H}_{2} \mathrm{O}$ the value of this angle depends on the nature of the channel. For A-type channels, one counts two values, 24.4 and $41.4^{\circ}$, whereas for B-type channels the unique value of $31.3^{\circ}$ is observed. $^{23}$

It is however difficult to rule on the reason of the structural difference between the two materials which can be considered as similar. The presence of fluorine in the framework in $\mathrm{Ga}(\mathrm{OH}, \mathrm{F})-\mathrm{MIL}-53$ np_ $\mathrm{H}_{2} \mathrm{O}$ even at 0.7 wt $\%$ and the shorter heating duration for the preparation of the crude form of GaMIL-53 could be underlined. It should also be noticed that the number of water molecules in the structure is slightly lower in the case of $\mathrm{Ga}(\mathrm{OH}, \mathrm{F})-\mathrm{MIL}-53$ np $\mathrm{H}_{2} \mathrm{O}(=0.83$, see Table S2, Supporting Information) than in the case of the hydrated GaMIL-53 (=1, see ref 23), possibly linked to the hydrophobic character of fluorinated materials.
We further investigated the nature of the difference between the various structures obtained experimentally by performing first-principle energy minimization calculations in the Density Functional Theory formalism. The level of theory used is stateof-the-art for the determination of MOF structures, coupling a hybrid exchange-correlation function and corrections accounting for dispersion interactions. The details of our calculations are reported in ref 35 .

We first characterized the structure of the large pore phase. As no experimental structure has been resolved for an adsorbate-free large pore material (either Ga-MIL-53 or $\mathrm{Ga}(\mathrm{OH}, \mathrm{F})-\mathrm{MIL}-53)$, we used as a starting point the experimental crystallographic structure of $\mathrm{Ga}(\mathrm{OH}, \mathrm{F})$ (BDC) $\cdot \mathrm{C}_{5} \mathrm{H}_{5} \mathrm{~N}$ synthesized by Vougo-Zanda et al. ${ }^{22}$ The published structure was edited to remove the guest pyridine molecules contained in its pores and add hydrogen atoms. The structure obtained was of Imma space group, which is consistent with the indexing of the X-ray diffraction patterns for the empty high-temperature phase of Ga-MIL-53. ${ }^{23}$ Energy minimization then yielded a structure in good agreement with the experimental unit cell parameters for MIL-53(Ga) ht of Volkinger et al. ${ }^{23}$ (unit cell volumes of 1452.7 vs $1479.7 \AA^{3}$; unit cell parameters are given in Table 2).

In a second time, we studied $\mathrm{Ga}(\mathrm{OH}, \mathrm{F})-\mathrm{MIL}-53$ _np_empty, a narrow-pore structure with no adsorbed molecule. Using the experimental structure for Ga-MIL-53, published by Volkringer et al., ${ }^{23}$ as a starting point, we minimized the atomic positions and unit cell parameters in the $C 2 / c$ space group. The energy minimization converged to a structure close to the experimental one, with a slight increase in unit cell volume (from 886.3 to $899.0 \AA^{3}$ ). Details of the unit cell parameters are given in Table 2. A geometrical analysis of accessible pore volume showed the resulting structure to be nonporous for a probe molecule of the size of water (kinetic diameter of $2.4 \AA$ ): the largest sphere that can access the pores has a diameter of $2.2 \AA$. We confirmed this geometrical analysis with Grand Canonical Monte Carlo simulations of water adsorption. No water molecule was adsorbed in the range of pressure up to $P_{\text {sat }}=3.5 \mathrm{kPa}$, the saturation pressure of water at $300 \mathrm{~K}$.

Finally, we turned our attention to the hydrated narrow-pore phase whose experimental structure was determined by X-ray diffraction, for both the Ga-MIL-53 and Ga(OH,F)-MIL-53 materials. Starting from the experimental structure of $\mathrm{Ga}$ $(\mathrm{OH}, \mathrm{F})-\mathrm{MIL}-53$ np_ $\mathrm{H}_{2} \mathrm{O}$ (space group $\mathrm{Cc}$ ), we first relaxed the hydrated structure, leading to a small shrinking of the unit cell (from 973.4 to $948.6 \AA^{3}$ ). We then removed the water molecules and optimized the empty structure: the material underwent a contraction of larger amplitude, yielding a final structure almost identical to the $\mathrm{Ga}(\mathrm{OH}, \mathrm{F})-\mathrm{MIL}-53$ np_empty structure discussed in the above paragraph (volume of 897.9 vs $899.0 \AA^{3}$; see Table 2 for all unit cell parameters). As a conclusion, our quantum chemistry calculations reveal that the 
conformation of the $\mathrm{Ga}(\mathrm{OH}, \mathrm{F})-\mathrm{MIL}-53$ np $\mathrm{H}_{2} \mathrm{O}$ framework is not a stable structure in the absence of adsorbed water molecules. Instead, removal of water spontaneously leads to the formation of $\mathrm{Ga}(\mathrm{OH}, \mathrm{F})-\mathrm{MIL}-53$ _np_empty.

We then performed the same analysis on the hydrated GaMIL-53 np material reported by the Ferrey group. The structure of this latter is slightly different from the Ga$(\mathrm{OH}, \mathrm{F})-\mathrm{MIL}-53$ np_ $\mathrm{H}_{2} \mathrm{O}$, in that it has been indexed in a double unit cell (and space group $P 2_{1} / c$ ). As discussed above, its super structure is composed of two different channels with two distinct crystallographic sites for water molecules (named sites $\mathrm{A}$ and $\mathrm{B}$ ). Upon removal of water molecules from hydrated Ga-MIL-53_np and energy minimization of the structure, we observed that the structure relaxation proceeds in two clearly separated stages. At first, the aromatic rings of the material rotate from their initial "twisted" position. This leads to more symmetric structure, in which the differentiation between channel types A and B has been lost. During later steps of the energy minimization, the framework then contracts into a nonporous structure, similarly to what was observed for $\mathrm{Ga}(\mathrm{OH}, \mathrm{F})-\mathrm{MIL}-53$ np_ $\mathrm{H}_{2} \mathrm{O}$. The final crystalline structure has, however, a lower unit cell volume $\left(V=840.7 \AA^{3}\right)$. We conclude again that $\mathrm{Ga}(\mathrm{OH}, \mathrm{F})-\mathrm{MIL}-53$ and Ga-MIL-53 behave in a similar fashion despite small structural differences which are still to be fully elucidated. The less reasonable structure obtained when starting from Ga-MIL-53 may be attributed to difficulties in the optimization of this complex molecular crystal, starting from a geometry that is more distorted than $\mathrm{Ga}(\mathrm{OH}, \mathrm{F})-\mathrm{MIL}-53$ np_ $\mathrm{H}_{2} \mathrm{O}$ (and twice its size). Further theoretical work on this aspect is ongoing.

2. In Situ XRD Characterization of Phase Transitions. The XRD patterns of $\mathrm{Ga}(\mathrm{OH}, \mathrm{F})-\mathrm{MIL}-53$ recorded at $303 \mathrm{~K}$ under air and vacuum are compared in Figure 2. It is worth

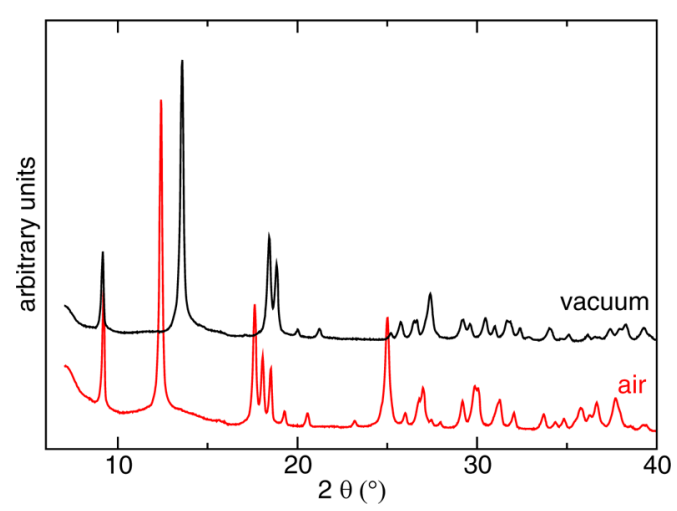

Figure 2. XRD patterns of $\mathrm{Ga}(\mathrm{OH}, \mathrm{F})-\mathrm{MIL}-53$ np_ $\mathrm{H}_{2} \mathrm{O}$ under air (red) and $\mathrm{Ga}(\mathrm{OH}, \mathrm{F})-\mathrm{MIL}-53$ _np_empty under vacuum (black) at room temperature.

noting that under vacuum all water molecules are desorbed from the sample at room temperature (see the thermodesorption curve shown in Supporting Information, Figure S6). Thus, the removal of water molecules from $\mathrm{Ga}(\mathrm{OH}, \mathrm{F})-\mathrm{MIL}$ 53 np $\mathrm{H}_{2} \mathrm{O}$ results in the formation of another phase, which has been previously observed and designated phase p1 at $T>$ $353 \mathrm{~K}$ under ambient atmosphere. ${ }^{9}$ The XRD pattern of this phase is the same as that observed for the structure referred to as MIL-53(Ga)_lt in ref 23 for which the structure was determined to be a narrow pore form of MIL-53. Our XRD data thus allow us to conclude that the stable form of the guest- free $\mathrm{Ga}(\mathrm{OH}, \mathrm{F})-\mathrm{MIL}-53$ at $303 \mathrm{~K}$ is a narrow pore form that we hereafter call $\mathrm{Ga}(\mathrm{OH}, \mathrm{F})-\mathrm{MIL}-53$ np_empty.

Further heating of the solid under vacuum in its thermal stability range (characterized by thermodesorption experiment, see Figure S6, Supporting Information) induces a progressive transformation of $\mathrm{Ga}(\mathrm{OH}, \mathrm{F})-\mathrm{MIL}-53$ np_empty into another phase, identical to phase 2 identified under air by Chaplais et al. ${ }^{9}$ The corresponding diffraction pattern is similar to those of MIL-53(Al)_ht and MIL-53(Cr)_ht, where it was identified as a large pore structure. ${ }^{36}$ This phase is designated here as $\mathrm{Ga}(\mathrm{OH}, \mathrm{F})-\mathrm{MIL}-53$ _lp. The np_empty $\rightarrow$ lp transformation under vacuum occurs in the same temperature range as for the sample heated in air: ${ }^{9}$ it begins at $423 \mathrm{~K}$, and it is complete at $523 \mathrm{~K}$ (Figure 3).

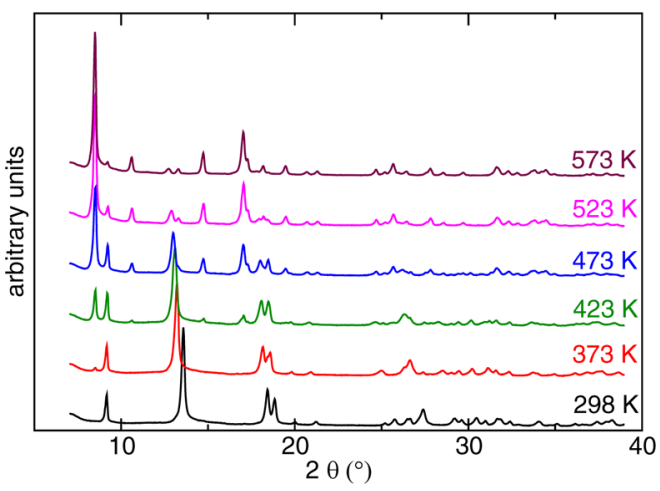

Figure 3. Evolution of the XRD patterns of $\mathrm{Ga}(\mathrm{OH}, \mathrm{F})-\mathrm{MIL}-53$ under vacuum as a function of temperature.

To verify the reversibility of the phase transition under vacuum, the sample was cooled from $573 \mathrm{~K}(\mathrm{Ga}(\mathrm{OH}, \mathrm{F})-\mathrm{MIL}$ 53 lp) to $303 \mathrm{~K}$. The XRD patterns of the sample were then recorded every $194 \mathrm{~min}$ (Figure 4). The cooling to $303 \mathrm{~K}$

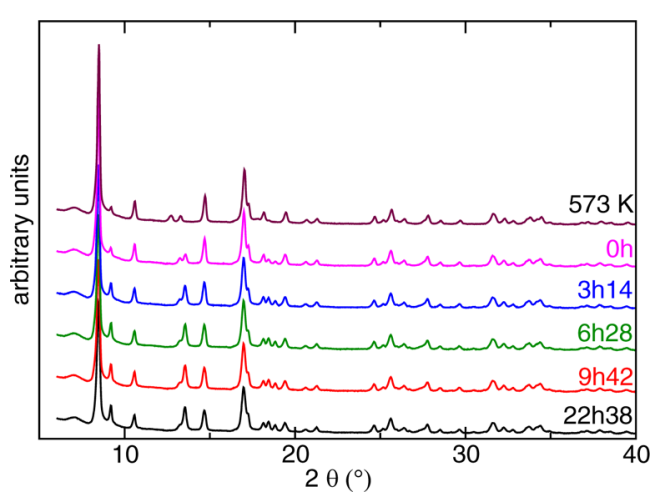

Figure 4. Evolution of the XRD pattern of $\mathrm{Ga}(\mathrm{OH}, \mathrm{F})-\mathrm{MIL}-53$ on cooling under vacuum from 573 to $303 \mathrm{~K}$.

induces a partial structural transformation of lp into np_empty as can be inferred from the appearance of the characteristic peaks (the most intense being the $(110)$ peak located at $2 \theta=$ $\left.13.5^{\circ}\right)$. On further aging at $303 \mathrm{~K}$, the intensity of the peaks of $\mathrm{Ga}(\mathrm{OH}, \mathrm{F})-\mathrm{MIL}-53$ np_empty slightly increases, but after ca. 6 $\mathrm{h}$ it remains constant. The structural phase of $\mathrm{Ga}(\mathrm{OH}, \mathrm{F})-\mathrm{MIL}$ 53 at $303 \mathrm{~K}$ under vacuum appears therefore to be dependent on the thermal history. After water desorption at $303 \mathrm{~K}$, the stable phase is the narrow pore form $\mathrm{Ga}(\mathrm{OH}, \mathrm{F})-\mathrm{MIL}$ 53 np_empty. By contrast after heating to $573 \mathrm{~K}$ and cooling, 
the solid consists of a mixture of lp and np_empty structures, with a majority of $l p$ structure. Such a behavior is indicative of a large temperature hysteresis in the structural transition for $\mathrm{Ga}(\mathrm{OH}, \mathrm{F})-\mathrm{MIL}-53$, similar to what has been observed in MIL$53(\mathrm{Al}) .^{37}$

3. In Situ FTIR Characterization of Phase Transitions. After outgassing under vacuum at room temperature, the infrared spectrum of $\mathrm{Ga}(\mathrm{OH}, \mathrm{F})-\mathrm{MIL}-53$ undergoes modifications in the wavenumber range $4000-400 \mathrm{~cm}^{-1}$ due to the phase transition from np_ $\mathrm{H}_{2} \mathrm{O}$ to $\mathrm{np}$ empty during dehydration. This structural transformation induces the disappearance of at least five vibrational bands characteristic of $\mathrm{Ga}(\mathrm{OH}, \mathrm{F})-\mathrm{MIL}-53$ np_ $\mathrm{H}_{2} \mathrm{O}$. The first one, located at 1626 $\mathrm{cm}^{-1}$, is assigned to the fundamental $\nu_{2}\left(\mathrm{H}_{2} \mathrm{O}\right)$ band of encapsulated water. The second one, at $1123 \mathrm{~cm}^{-1}$, corresponds to the $\delta(\mathrm{OH})$ band of the $\mu_{2}$-hydroxo group hydrogen bonded to adsorbed water molecules $\left[\mathrm{H}_{2} \mathrm{O} \cdots \mathrm{H}-\right.$ $\left.\mathrm{O}(\mathrm{Ga})_{2}\right]$. The last three bands, located at 983, 624, and 582 $\mathrm{cm}^{-1}$, can also be assigned to bands arising from the interaction of water with $\mathrm{Ga}(\mathrm{OH}, \mathrm{F})-\mathrm{MIL}-53$. All other vibrational bands are almost unchanged upon dehydration at room temperature.

Upon heating under vacuum, the infrared spectrum of $\mathrm{Ga}(\mathrm{OH}, \mathrm{F})-\mathrm{MIL}-53 \mathrm{np}$ empty undergoes further strong modifications due to the np_empty-lp structural transition. Over the nineteen vibrational bands examined in the range 2000$400 \mathrm{~cm}^{-1}$, only six are not modified during the phase transition. Ten vibrational bands are blue- or red-shifted by jump at either 453 or at $499 \mathrm{~K}$, depending on the nature of the vibration (Figure 5). The shifts are at least $5 \mathrm{~cm}^{-1}$ for the band referenced as $\nu 17 \mathrm{~B}$ and located at $890 \mathrm{~cm}^{-1}$, and they can reach $19 \mathrm{~cm}^{-1}$ for the $\nu_{\text {as }}\left(\mathrm{CO}_{2}^{-}\right)$vibrational mode of the terephthalate ligand that is located at $1546 \mathrm{~cm}^{-1}$ in the np_empty form. As specified by Volkringer et al. ${ }^{23}$ for the vibrational band located at around $1020 \mathrm{~cm}^{-1}$ and referenced as $18 \mathrm{~A}$ in Figure 5, these shifts reflect the opening phenomenon of the $\mathrm{Ga}(\mathrm{OH}, \mathrm{F})-\mathrm{MIL}-53$ np_empty network to give the lp phase. One other band located at $544 \mathrm{~cm}^{-1}$ disappears after heating above $453 \mathrm{~K}$ (Figure S7, Supporting Information), and two new bands located at 513 and $580 \mathrm{~cm}^{-1}$, characteristic of the lp phase, appear at temperature higher than $499 \mathrm{~K}$ (Figure S8, Supporting Information).

From this analysis of the location of vibrational bands as a function of temperature, it is clear that the $n p$ empty and $\mathrm{lp}$ phases exist as pure phases in the temperature ranges below $453 \mathrm{~K}$ and above $499 \mathrm{~K}$, respectively. Between 453 and $499 \mathrm{~K}$, the coexistence of characteristic bands of the two structures indicates the presence of a mixture of the np_empty and lp phases.

The values of the temperature of phase transition determined by in situ FTIR spectroscopy and XRD are in good agreement, as can be seen on the diagram shown in Figure 6. The small discrepancy between the values of the temperature from which the lp phase appears can be attributed to differences of sensitivity of the techniques or to the accuracy on measured values of temperature from one technique to another.

4. Calorimetric Measurements. To shed light onto the energetics of the phase transitions observed in $\mathrm{Ga}(\mathrm{OH}, \mathrm{F})-\mathrm{MIL}$ 53, we performed calorimetric measurements upon dehydration and heating of the material. The heat absorbed during the dehydration step led to an integral enthalpy of dehydration close to $+49 \mathrm{~kJ} \mathrm{~mol}^{-1}$ of water desorbed. From this value, close to the standard vaporization enthalpy of water $\left(+44 \mathrm{~kJ} \mathrm{~mol}^{-1}\right)$, we could conclude that the water is not strongly bound to the

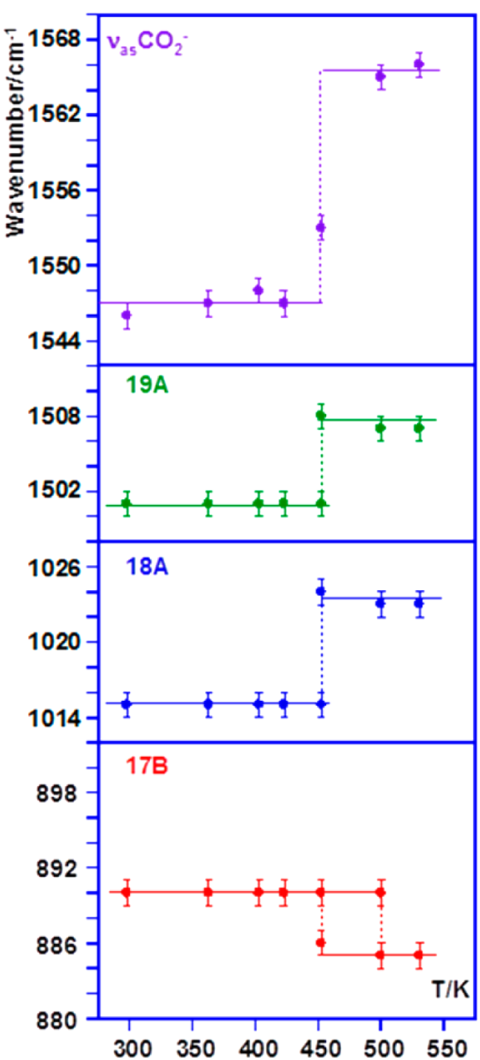

Figure 5. Variation of the position of the $\nu_{\text {as }}\left(\mathrm{CO}_{2}^{-}\right)$vibrational modes and the ring stretching $\nu(\mathrm{C}=\mathrm{C})$ (referenced as $\nu 19 \mathrm{~A}$ ) vibrational mode, the $\delta(\mathrm{C}-\mathrm{H})$ (referenced as $\nu 18 \mathrm{~A})^{40}$ in plane vibrational deformation modes, and the $\gamma(\mathrm{C}-\mathrm{H})$ (referenced as $\nu 17 \mathrm{~B})^{40}$ out of plane vibrational deformation modes of the terephthalate ligands of $\mathrm{Ga}(\mathrm{OH}, \mathrm{F})-\mathrm{MIL}-53$ with temperature, under vacuum.

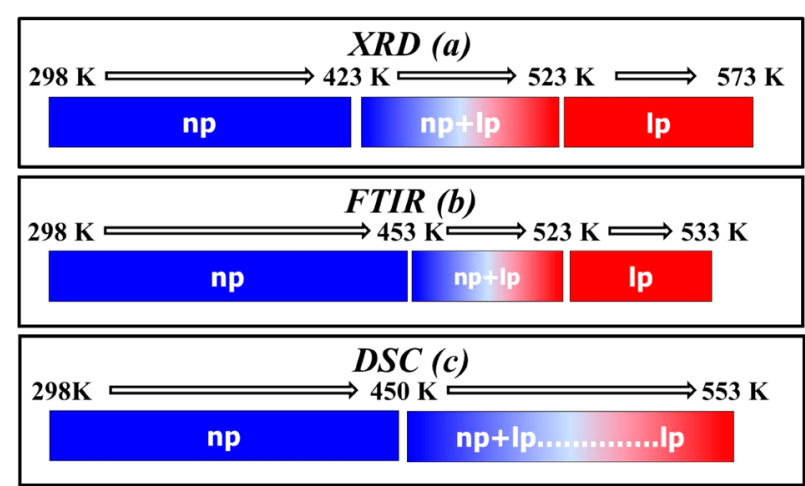

Figure 6. Schematic diagram reporting the values of temperature of the phase transition of $\mathrm{Ga}(\mathrm{OH}, \mathrm{F})-\mathrm{MIL}-53$ determined under vacuum by XRD (a), FTIR (b), and DSC (c) (np for np_empty: narrow pore form; lp: large pore form).

surface. Moreover, this integral enthalpy is the sum of two thermal effects: the endothermic desorption of water and the exothermic phase transition from $\mathrm{np} \mathrm{H}_{2} \mathrm{O}$ to $\mathrm{np}$ empty structures. So, the energy of interaction between the water molecules and the channel surface should be greater than $49 \mathrm{~kJ}$ $\mathrm{mol}^{-1}$.

The temperature dependence of the heat capacity of anhydrous $\mathrm{Ga}(\mathrm{OH}, \mathrm{F})-\mathrm{MIL}-53$ is shown in Figure 7 (green circles): it ranges from 50 to $180 \mathrm{~J} \mathrm{~K}^{-1} \mathrm{~mol}^{-1}$. For comparison, the standard heat capacity of gallium oxide $\mathrm{Ga}_{2} \mathrm{O}_{3}$ is equal to 


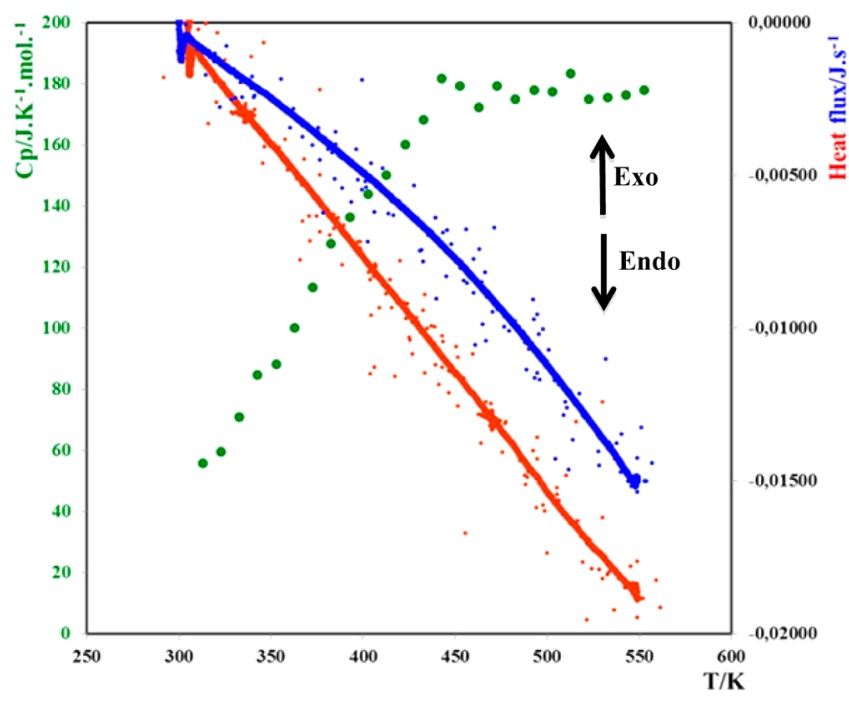

Figure 7. Heat capacity (green curve) of $\mathrm{Ga}(\mathrm{OH}, \mathrm{F})-\mathrm{MIL}-53$ and heat flow measured by the calorimeter during heating from 298 to $553 \mathrm{~K}$ under dynamic vacuum (blue curve: sample experiment with $\mathrm{Ga}(\mathrm{OH}, \mathrm{F})-\mathrm{MIL}-53$; red curve: blank experiment without sample).

83.6 $\mathrm{J} \mathrm{K}^{-1} \mathrm{~mol}^{-1}$ at $323 \mathrm{~K}^{38}$ and that of terephthalate acid is equal to $199.6 \mathrm{~J} \mathrm{~K}^{-1} \mathrm{~mol}^{-1}$ at $298 \mathrm{~K}^{39}$ At $450 \mathrm{~K}$, the slope of the $C_{p}-T$ curve changes and remains surprisingly constant between 450 and $553 \mathrm{~K}$. Comparing with XRD and FTIR results, this change of slope can be attributed to the appearance of an lp phase. The constancy of $C_{p}$ above $450 \mathrm{~K}$ may be explained by the endothermal np_empty $\rightarrow$ lp phase transition, which interferes with $C_{p}$ measurements. This suggests that the $\mathrm{np}$ empty $\rightarrow \mathrm{lp}$ transition occurs gradually from a temperature of about $450 \mathrm{~K}$ and that it is complete at $553 \mathrm{~K}$. The existence of a biphasic domain characterized by DSC is in good agreement with experimental results obtained by in situ XRD and FTIR (Figure 6c).

The heat flux was measured by the calorimeter upon heating $\mathrm{Ga}(\mathrm{OH}, \mathrm{F})-\mathrm{MIL}-53$ from 298 to $553 \mathrm{~K}$ under dynamic vacuum (blue curve in Figure 7) and compared to a blank experiment performed without sample (red curve). While the variation of heat flux for the blank experiment is linear with temperature, this is not the case in the presence of the sample: an endothermic effect is observed. This means that the enthalpy does not jump at the phase transition, which takes place at around $450 \mathrm{~K}$, but varies continuously upon heating above this temperature.

As it is not possible to measure directly the enthalpy change of the np_empty $\rightarrow$ lp phase transition, we estimated it in two steps. We thus measured the integral enthalpy of dehydration under vacuum of $\mathrm{Ga}(\mathrm{OH}, \mathrm{F})-\mathrm{MIL}-53$ at room temperature (np $\mathrm{H}_{2} \mathrm{O} \rightarrow \mathrm{np}$ empty transition), as well as that of hydration of $\overline{\mathrm{Ga}}(\mathrm{OH}, \mathrm{F})-\mathrm{MIL}-53$ at room temperature after activation at $553 \mathrm{~K}\left(\mathrm{lp} \rightarrow \mathrm{np} \mathrm{H}_{2} \mathrm{O}\right.$, lp being metastable at room temperature)

$$
\Delta H_{\text {np.empty } \rightarrow \text { lp }}=-\left(\Delta H_{\text {np.H2O } \rightarrow \text { np.empty }}+\Delta H_{\mathrm{lp} \rightarrow \text { np.H2O }}\right)
$$

Results are collected in Table 3. From this estimation, the integral enthalpy of the phase transition from np_empty to lp is about $5.5 \mathrm{~kJ} \mathrm{~mol}^{-1}$. This value is only an estimate because the interaction energy of water with the np_empty phase is certainly different from that observed with the lp phase.
Table 3. Enthalpy of Dehydration of Ga(OH,F)-MIL-53 at 298 K under Dynamic Vacuum, Enthalpy of Hydration of $\mathrm{Ga}(\mathrm{OH}, \mathrm{F})-\mathrm{MIL}-53$ at $298 \mathrm{~K}$ under $18 \mathrm{hPa}$ after Activation at $553 \mathrm{~K}$, and Enthalpy of the Phase Transition from np_empty to $1 p$

\begin{tabular}{|c|c|}
\hline type of transformation & enthalpy change $/ \mathrm{kJ} \mathrm{mol}^{-1}$ \\
\hline $\begin{array}{l}\text { dehydration and } \mathrm{np} \mathrm{H}_{2} \mathrm{O} \rightarrow \text { np } \\
\text { transition of } \mathrm{Ga}(\overline{\mathrm{OH}}, \mathrm{F})-\mathrm{MIL}-5 \overline{3}\end{array}$ & +49.3 \\
\hline $\begin{array}{l}\text { hydration and lp } \rightarrow \text { np_ } \mathrm{H}_{2} \mathrm{O} \text { phase transition of } \\
\mathrm{Ga}(\mathrm{OH}, \mathrm{F})-\mathrm{MIL}-53\end{array}$ & -54.9 \\
\hline $\mathrm{np}$ empty $\rightarrow$ lp phase transition & +5.6 \\
\hline
\end{tabular}

\section{CONCLUSION}

In this paper, we used a wide array of experimental techniques over the 300-600 K temperature range to study the solid-solid phase transition in $\mathrm{Ga}(\mathrm{OH}, \mathrm{F})-\mathrm{MIL}-53$ under vacuum. Results obtained from in situ X-ray diffraction (XRD), in situ Fourier transform infrared spectroscopy (FTIR), and differential scanning calorimetry (DSC) were all found to be in good agreement. We showed that, in addition to the hydrated structure resulting from the synthesis, $\mathrm{Ga}(\mathrm{OH}, \mathrm{F})-\mathrm{MIL}-53$ exhibits two different phases under vacuum: a nonporous narrow-pore phase (np), thermodynamically favored at lower temperature, and a large-pore phase (lp), favored at high temperature. Experimental measurements (both XRD and FTIR) upon heating and cooling $\mathrm{Ga}(\mathrm{OH}, \mathrm{F})-\mathrm{MIL}-53$ revealed large hystereses of the temperature-induced structural transitions, highlighting the importance of the material's thermal history to its physical and chemical properties. Finally, geometry optimization of the experimental crystallographic structures within the framework of the density functional theory enabled us to conclude that the hydrated phase at low temperature is not a stable structure in the absence of adsorbed water molecules. Instead, the hydrated structure is a swollen variant of the narrow-pore phase, where the framework has expanded to accommodate water molecules. Given that the behavior of guest-free $\mathrm{Ga}(\mathrm{OH}, \mathrm{F})-\mathrm{MIL}-53$ as a function of temperature has now been established, work is ongoing to assess its behavior in the presence of adsorbates and particularly in the presence of water in the vapor or liquid state.

Finally, it is now clear that despite some small structural differences $\mathrm{Ga}(\mathrm{OH}, \mathrm{F})-\mathrm{MIL}-53$ should be considered as displaying a similar physical chemistry behavior to the standard Ga-MIL-53, especially with respect to the phase behavior and the breathing phenomenon. It turns out that, just like the other MIL-53 (M); $\mathrm{M}=\mathrm{Cr}, \mathrm{Al}, \mathrm{Fe}, . .$. materials, the empty gallium based MIL-53 material exhibits two, and only two, stable phases, something that was not clear up to now.

\section{ASSOCIATED CONTENT}

\section{S Supporting Information}

Additional experimental details. This material is available free of charge via the Internet at http://pubs.acs.org.

\section{AUTHOR INFORMATION}

\section{Corresponding Author}

*E-mail: anne.boutin@ens.fr. Tel.: 33 - 144322429.

\section{Notes}

The authors declare no competing financial interest. 


\section{ACKNOWLEDGMENTS}

The authors gratefully acknowledge Dr. Didier LE NOUEN (LCOB - UHA - EA4566) for carrying out the liquid state NMR experiments. Funding from the Agence Nationale de la Recherche under project "SOFT-CRYSTAB" (ANR-2010BLAN-0822) is acknowledged.

\section{REFERENCES}

(1) Horike, S.; Shimomura, S.; Kitagawa, S. Soft Porous Crystals. Nature Chem. 2009, 1, 695-704.

(2) Férey, G.; Serre, C. Large Breathing Effects in ThreeDimensional Porous Hybrid Matter: Facts, Analyses, Rules and Consequences. Chem. Soc. Rev. 2009, 38, 1380-1399.

(3) Kitagawa, S.; Matsuda, R. Chemistry of Coordination Space of Porous Coordination Polymers. Coord. Chem. Rev. 2007, 251, 24902509.

(4) Férey, G. Swelling Hybrid Solids. Z. Anorg. Allg. Chem. 2012, 638, 1897-1909.

(5) Long, J. R.; Yaghi, O. M. The Pervasive Chemistry of MetalOrganic Frameworks. Chem. Soc. Rev. 2009, 38, 1213-1214.

(6) Férey, G. Hybrid Porous Solids: Past, Present, Future. Chem. Soc. Rev. 2008, 37, 191-214.

(7) Millange, F.; Serre, C.; Férey, G. Synthesis, Structure Determination and Properties of MIL-53(as) and MIL-53(ht): The First $\mathrm{Cr}$ (III) Hybrid Inorganic-Organic Microporous Solids. Chem. Commun. 2002, 822-823.

(8) Horcajada, P.; Serre, C.; Maurin, G.; Ramsahye, N. A.; Balas, F.; Vallet-Regi, M.; Sebban, M.; Taulelle, F.; Férey, G. Flexible Porous Metal-Organic Frameworks for a Controlled Drug Delivery. J. Am. Chem. Soc. 2008, 130, 6774-6780.

(9) Chaplais, G.; Simon-Masseron, A.; Porcher, F.; Lecomte, C.; Bazer-Bachi, D.; Bats, N.; Patarin, J. IM-19: A New Flexible Microporous Gallium Based-MOF Framework with Pressure- and Temperature-Dependent Openings. Phys. Chem. Chem. Phys. 2009, 11, 5241-5245.

(10) Coudert, F.-X.; Jeffroy, M.; Fuchs, A. H.; Boutin, A.; MellotDraznieks, C. Thermodynamics of Guest-Induced Structural Transitions in Hybrid Organic-Inorganic Frameworks. J. Am. Chem. Soc. 2008, 130, 14294-14302.

(11) Boutin, A.; Springuel-Huet, M.-A.; Nossov, A.; Gédéon, A.; Loiseau, T.; Volkringer, C.; Férey, G.; Coudert, F.-X.; Fuchs, A. H. Breathing Transitions in MIL-53(Al) Metal-Organic Framework Upon Xenon Adsorption. Angew. Chem., Int. Ed. 2008, 48, 8314-8317.

(12) Liu, Y.; Her, J.-Y.; Dailly, A.; Ramirez-Cuesta, A. J.; Neumann, D. A.; Brown, C. M. Reversible Structural Transition in MIL-53 with Large Temperature Hysteresis. J. Am. Chem. Soc. 2008, 130, 1181311818 .

(13) Beurroies, I.; Boulhout, M.; Llewellyn, P. L.; Kuchta, B.; Férey, G.; Serre, C.; Denoyel, R. Using Pressure to Provoke the Structural Transition of Metal-Organic Frameworks. Angew. Chem., Int. Ed. 2010, 49, 7526-7529.

(14) Maes, M.; Vermoortele, F.; Alaerts, L.; Couck, S.; Kirschhock, C. E. A.; Denayer, J. F. M.; De Vos, D. E. Separation of Styrene and Ethylbenzene on Metal-Organic Frameworks: Analogous Structures with Different Adsorption Mechanisms. J. Am. Chem. Soc. 2010, 132, 15277-15285.

(15) Millange, F.; Guillou, N.; Walton, R. I.; Grenèche, J.-M.; Margiolaki, I.; Férey, G. Effect of the Nature of the Metal on the Breathing Steps in MOFs with Dynamic Frameworks. Chem. Commun. 2008, 4732-4734.

(16) Mowat, J. P. S.; Seymour, V. R.; Griffin, J. M.; Thompson, S. P.; Slawin, A. M. Z.; Fairen-Jimenez, D.; Düren, T.; Ashbrook, S. E.; Wright, P. A. A Novel Structural Form of MIL-53 Observed for the Scandium Analogue and Its Response to Temperature Variation and $\mathrm{CO}_{2}$ Adsorption. Dalton Trans. 2012, 41, 3937-3941.

(17) Nouar, F.; Devic, T.; Chevreau, H.; Guillou, N.; Gibson, E.; Clet, G.; Daturi, M.; Vimont, A.; Grenèche, J.-M.; Breeze, M. I.; Walton, R. I.; Llewellyn, P. L.; Serre, C. Tuning the Breathing
Behaviour of MIL-53 by Cation Mixing. Chem. Commun. 2012, 48, 10237-10239.

(18) Devic, T.; Horcajada, P.; Serre, C.; Salles, F.; Maurin, G.; Moulin, B.; Heurtaux, D.; Clet, G.; Vimont, A.; Grenèche, J.-M.; Le Ouay, B.; Moreau, F.; Magnier, E.; Filinchuk, Y.; Marrot, J.; Lavalley, J.-C.; Daturi, M.; Férey, G. Functionalization in Flexible Porous Solids: Effects on the Pore Opening and the Host-Guest Interactions. J. Am. Chem. Soc. 2010, 132, 1127-1136.

(19) Biswas, S.; Rémy, T.; Couck, S.; Denysenko, D.; Rampelberg, G.; Denayer, J. F. M.; Volkmer, D.; Detavernier, C.; Van Der Voort, P. Partially Fluorinated MIL-47 and Al-MIL-53 Frameworks: Influence of Functionalization on Sorption and Breathing Properties. Phys. Chem. Chem. Phys. 2013, 15, 3552-3561.

(20) Pera-Titus, M.; Lescouet, T.; Aguado, S.; Farruseng, D. Quantitative Characterization of Breathing upon Adsorption for a Series of Amino-Functionalized MIL-53. J. Phys. Chem. C 2012, 116, 9507-9516.

(21) Lescouet, T.; Kockrick, E.; Bergeret, G.; Pera-Titus, M.; Aguado, S.; Farruseng, D. Homogeneity of Flexible Metal-Organic Frameworks Containing Mixed Linkers. J. Mater. Chem. 2012, 22, 1028710293.

(22) Vougo-Zanda, M.; Huang, J.; Anokhina, E.; Wang, X.; Jacobson, A. J. Tossing and Turning: Guests in the Flexible Frameworks of Metal(III) Dicarboxylates. Inorg. Chem. 2008, 47, 11535-11542.

(23) Volkringer, C.; Loiseau, T.; Guillou, N.; Férey, G.; Elkaïm, E.; Vimont, A. XRD and IR Structural Investigations of a Particular Breathing Effect in the MOF-Type Gallium Terephthalate MIL53(Ga). Dalton Trans. 2009, 2241-2249.

(24) Chaplais, G.; Simon-Masseron, A.; Patarin, J.; Bats, N.; BazerBachi, D. Nouveau matériau hybride organique-inorganique et son procédé de préparation. FR Patent 2927911, August 28, 2009.

(25) Chaplais, G.; Simon-Masseron, A.; Patarin, J.; Bats, N.; BazerBachi, D. Nouveau matériau hybride organique-inorganique et son procédé de préparation. FR Patent 2927912, August 28, 2009.

(26) Liu, L.; Wang, X.; Jacobson, A. J. AlF 1,4-Benzenedicarboxylate: Synthesis and Absorption Properties. Dalton Trans. 2010, 39, 17221725.

(27) (a) Larson, A. C.; Von Dreele, R. B. General Structure Analysis System, Los Alamos National Laboratory Report LAUR 86-748; Los Alamos National Laboratory: New Mexico, 2000. (b) Toby, B. H. EXPGUI, a Graphical User Interface for GSAS. J. Appl. Crystallogr. 1994, 34, 210-213.

(28) Dovesi, R.; Orlando, R.; Civalleri, B.; Roetti, C.; Saunders, V. R.; Zicovich-Wilson, C. M. CRYSTAL: a Computational Tool for the Ab Initio Study of the Electronic Properties of Crystals. Z. Kristallogr. 2005, 220, 571-573.

(29) Becke, A. D. Density-Functional Thermochemistry. III. The Role of Exact Exchange. J. Chem. Phys. 1993, 98, 5648-5652.

(30) Lee, C.; Yang, W.; Parr, R. G. Development of the Colle-Salvetti Correlation-Energy Formula Into a Functional of the Electron Density. Phys. Rev. B 1988, 37, 785-789.

(31) Grimme, S. Semiempirical GGA-Type Density Functional Constructed with a Long-Range Dispersion Correction. J. Comput. Chem. 2006, 27, 1787-1799.

(32) Gatti, C.; Saunders, V. R.; Roetti, C. Crystal Field Effects on the Topological Properties of the Electron Density in Molecular Crystals: The Case of Urea. J. Chem. Phys. 1994, 101, 10686-10696.

(33) Catti, M.; Valerio, G.; Dovesi, R.; Causa, M. QuantumMechanical Calculation of the Solid-State Equilibrium $\mathrm{MgO}+\alpha$ $\mathrm{Al} 2 \mathrm{O} 3 \rightleftarrows \mathrm{MgAl} 2 \mathrm{O} 4$ (Spinel) Versus Pressure. Phys. Rev. $B$ 1994, 49, 14179-14187.

(34) Pandey, R.; Jaffe, J. E.; Harrison, N. M. Ab-Initio Study of HighPressure Phase-Transition in GaN. J. Phys. Chem. Solids 1994, 55, 1357-1361.

(35) Ortiz, A. U.; Boutin, A.; Fuchs, A. H.; Coudert, F.-X. Anisotropic Elastic Properties of Flexible Metal-Organic Frameworks: How Soft are Soft Porous Crystals? Phys. Rev. Lett. 2012, 109, 195502.

(36) Loiseau, T.; Serre, C.; Huguenard, C.; Fink, G.; Taulelle, F.; Henry, M.; Bataille, T.; Férey, G. A Rationale for the Large Breathing 
of the Porous Aluminum Terephthalate (MIL-53) Upon Hydration. Chem.-Eur. J. 2004, 10, 1373-1382.

(37) Liu, Y.; Her, J.-H.; Dailly, A.; Ramirez-Cuesta, A. J.; Neumann, D. A.; Braun, C. M. Reversible Structural Transition in MIL-53 with Large Temperature Hysteresis. J. Am. Chem. Soc. 2008, 130, 1181311818.

(38) Satoh, S.; Sogabe, T. The Heat Capacities of Some Organic Compounds Containing Nitrogen and the Atomic Heat of Nitrogen. Sci., Pap. Inst. Phys. Chem. Res. (Tokyo) 1941, 38, 246-251.

(39) Rossini, F.D.; Wagman, D.D.; Evans, W.H.; Levine, S.; Jaffe, I. Selected values of chemical thermodynamics properties; United States Government Printing Office: Washington DC, 1952.

(40) Wilson, E. B. The Normal Modes and Frequencies of Vibration of the Regular Plane Hexagon Model of the Benzene Molecule. Phys. Rev. 1934, 45, 706-714. 